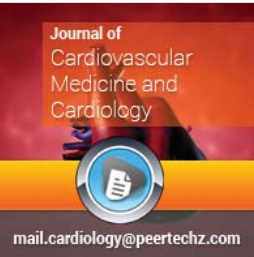

Medical Group

Journal of Cardiovascular Medicine and

Cardiology

DOI:http://dx.doi.org/10.17352/jcmc

Edyta Dziadkowiak*, Justyna

Chojdak, Maciej Guziński, Katarzyna

Lewczuk, Leszek Noga, Alicja

Kostecka and Bogusław Paradowski

Wroclaw Medical University 213 Street Borowska, Wroclaw, Poland

Received: 22 October, 2018

Accepted: 25 October, 2018

Published: 26 October, 2018

*Corresponding author: Edyta Dziadkowiak, Wroclaw Medical University 213 Street Borowska, Wroclaw, Poland, Tel: 48-71-731-3110; Fax: 48-71-731-3109; Email: edbkowal@gmail.com

Keywords: Troponin; Modified rankin scale; Acute phase of stroke

https://www.peertechz.com

Check for updates

\section{Research Article \\ Troponin Levels in Patients in Acute Phase of Stroke}

\section{Abstract}

Background and Purpose: The purpose of this study was to assess the correlation of cTn levels in the acute phase of ischemic stroke with the extent of stroke, the degree of disability assessed on the modified Rankin Scale, and their prognostic significance.

Methods: Patients were divided into 3 groups: (A) ischemic strokes, (B) ischemic strokes followed by hemorrhagic transformation, and (C) hemorrhagic strokes, excluding patients with symptoms of acute coronary syndrome. Cardiac troponin levels (cTn) were determined by venipuncture using the Abbott ARCHITECT STAT hs Troponin-I assay.

Results: Seventy-four percent of the patients (128/173) were diagnosed with ischemic stroke, $14 \%(24 / 173)$ with ischemic stroke followed by hemorrhagic transformation, and $12 \%(21 / 173)$ with hemorrhagic stroke. The mean troponin level was $0.21 \pm 1.15 \mathrm{ng} / \mathrm{mL}$ in the whole group (from 0 up to 12.4 $\mathrm{ng} / \mathrm{mL}$ ), while in the group with ischemic stroke the mean troponin level was $0.15 \pm 076 \mathrm{ng} / \mathrm{mL}$ (from 0 up to $7.9 \mathrm{ng} / \mathrm{mL}$ ). In 79/128 patients with ischemic stroke, troponin values were normal. Troponin levels were significantly correlated with the modified Rankin Scale on admission and on the day of discharge $(p=$ 0.0001 ). Hyperlipidemia present in 104 patients had a statistically significant effect on statistically higher troponin levels $(0.15 \pm 0.80 \mathrm{ng} / \mathrm{mL})$. In $48 \%$ of the cases, vascular lesions involved the vascular area of the middle cerebral artery (83 patients), while the rarest ones were in the basal ganglia area (4 patients). In the case of cerebellum changes, statistically significantly lower troponin levels were found than in the other groups $(p=0.050)$.

Conclusions: A moderate increase in troponin was observed in patients with cerebral stroke. Elevated troponin levels indicated the lesion size and correlated with the degree of disability. High troponin levels can be a prognostic factor in the course of stroke.

\section{Introduction}

Troponins (Tn) are regulatory protein complexes that control the activity of myosin and actin. Troponin C, troponin $\mathrm{T}$, and troponin I constitute elements of the troponintropomyosin complex in thin filaments of myofibrils in the myocardium and striated muscles. Heart isoforms of troponin $\mathrm{T}$ (cTnT) and troponin I (cTnI) have a different amino acid composition and structure from isoforms found in skeletal muscles. Their presence in blood is a specific and sensitive indicator of damage to myocardial cells. They can be also useful in detecting damage to cardiomyocytes in, among others, massive pulmonary embolism with accompanying right ventricular overload. An increase in cTn levels in patients with stable coronary arterial disease indicates an increased risk of cardiovascular death $[1,2]$. A false positive result may be caused by the presence of rheumatoid factor or heterophilic antibodies $[3,4]$. Increased cTn values also occurred in patients with stroke [5-7]. Elevated troponin levels in patients with stroke are lower than in patients with acute coronary syndrome. In a study by VanHouten et al., troponin levels in stroke ranged from 0.000 to $94.170 \mathrm{ng} / \mathrm{mL}$. In acute coronary syndrome, they ranged from 0.000 to $1,897.92 \mathrm{ng} / \mathrm{mL}$ [8]. According to the guidelines of the American Heart Association, measurement of cardiac troponins (cTn) is recommended in all patients with ischemic stroke [9].

The purpose of this study was to assess the correlation of cTn levels in the acute phase of ischemic stroke with the extent of stroke, the degree of disability assessed on the modified Rankin Scale and their prognostic significance.

\section{Materials and Methods}

In this study based on medical documentation, 173 patients of the University Clinic of Neurology diagnosed with stroke according to the WHO definition and ICD 10 [10], classification were retrospectively assessed. Patients were divided into 3 groups: (A) ischemic strokes, (B) ischemic strokes followed 
by hemorrhagic transformation, and (C) hemorrhagic strokes, excluding patients with symptoms of acute coronary syndrome. Cardiac troponin levels (cTn) were determined by venipuncture using the Abbott ARCHITECT STAT hs Troponin-I assay, which meets the criteria of a high sensitivity test as defined in the publication "IFCC Task Force on Clinical Applications of Cardiac Biomarkers," i.e. detection of concentrations below the 99th percentile and estimation at $<10 \%$ of total imprecision expressed by coefficient of variation (CV) in the 99th percentile. Cardiac troponin concentrations determined in $\mathrm{pg} / \mathrm{mL}$ units were converted to $\mathrm{ng} / \mathrm{mL}$ units. The detection threshold was set at $<0.01 \mathrm{ng} / \mathrm{mL}$ and the cut-off point for myocardial infarction and abnormal values were set at $0.028 \mathrm{ng} / \mathrm{mL}$.

Each patient had a standard 12-lead ECG. We also analyzed the presence of vascular risk factors (hypertension, diabetes, atherosclerosis, lipid disorders, atrial fibrillation, and nicotine addiction) and history of vascular incidents. The degree of disability was assessed using the modified Rankin Scale on the day of admission and after hospitalization [11,12]. Patients treated with recombinant tissue plasminogen activator (rtTPA) were isolated from the group with ischemic stroke.

The extent of the stroke lesion and the presence of leukoaraiosis were assessed on the basis of a CT scan performed on the first or second day of stroke. In the case of ischemic stroke, the size of the stroke lesion was rated on a scale from 0 (no change) to 10 (the whole hemisphere is occupied). For hemorrhagic strokes, the size of a lesion was determined using axial scans. Four lesion sizes were distinguished: up to $2 \mathrm{~cm}$, up to $4 \mathrm{~cm}$, up to $6 \mathrm{~cm}$, and above $6 \mathrm{~cm}(1 \mathrm{~cm}-1$ point). Regarding the lesion location, 5 areas of vascularity were distinguished as well as lesions resembling lacunar strokes:

1. MCA vascularity,

2. Vascularity of 2 arteries of the anterior circulation (ACA),

3. PCA vascularity,

4. Vascularity of 2 arteries of the basal ganglia area,

5. Changes in the cerebellum, and

6. Lacunar lesions.

The analysis involved CT scanning conducted with the use of 64- and 16-row CT scanners (GE Healthcare) with isotopic resolution (3D) and a layer thickness of $0.6 \mathrm{~mm}$.

All the analyzed tests were performed within routine diagnostic inpatient procedures. Each patient has signed the informed consent to these procedures on admission to the hospital, as well as the informed consent for insight into their medical records for didactic or research reasons.

\section{Statistical tools}

The statistical analysis was carried out using Statistica 10 software. Due to the lack of normal distribution of troponin values, non-parametric methods were used in calculations.
The existence of a correlation was investigated using the Spearman's rank correlation coefficient. For all tests used in the study, statistical significance was set at $\mathrm{p}<0.05$.

\section{Results}

The mean age of the whole group of patients was $73.32 \pm$ 13.66 (27-95), including $45 \%$ of men (77/173) aged $69.13 \pm$ 14.01 years and $55 \%$ of women $(96 / 173)$ aged $76.68 \pm 12.24$ years. Seventy-four percent of the patients (128/173) were diagnosed with ischemic stroke, $14 \%$ (24/173) with ischemic stroke followed by hemorrhagic transformation, and $12 \%$ (21/173) with hemorrhagic stroke. Ischemic and hemorrhagic lesions mainly concerned the area of middle cerebral artery vascularization (79 patients). In 25 patients, quantitative disturbances of consciousness were observed, predominantly in cases of ischemic stroke. The characteristics of the examined groups are presented in table 1.

The mean troponin level was $0.21 \pm 1.15 \mathrm{ng} / \mathrm{mL}$ in the whole group (from 0 up to $12.4 \mathrm{ng} / \mathrm{mL}$ ), while in the group with ischemic stroke the mean troponin level was $0.15 \pm 076 \mathrm{ng} /$ $\mathrm{mL}$ (from o up to $7.9 \mathrm{ng} / \mathrm{mL}$ ). In $79 / 128$ patients with ischemic stroke, troponin values were normal. Treatment with recombinant tissue plasminogen activator had no significant effect on troponin levels in 36 patients. In the group with ischemic stroke followed by hemorrhagic transformation, troponin levels were $0.60 \pm 2.55 \mathrm{ng} / \mathrm{mL}$ (from 0 up to $12.54 \mathrm{ng}$ / $\mathrm{mL}$ ). In patients with hemorrhagic stroke, troponin levels were $0.12 \pm 0.40 \mathrm{ng} / \mathrm{mL}$. Troponin values in individual groups are presented in table 2 .

The highest mean troponin values were in 41 deceased patients and amounted to $0.68 \pm 2.30 \mathrm{ng} / \mathrm{mL}$, which was statistically significant $(\mathrm{p}=0.003)$. Among the dead, 34 patients were diagnosed with ischemic stroke ( 13 of which were followed by hemorrhagic transformation) and 7 patients had hemorrhagic stroke.

In $64 \%$ of patients (110/173), troponin levels were found to be normal. In $36 \%$ of patients (63/173), troponin levels were abnormal (>0.028 ng/mL) and amounted to $0.57 \pm 1.89 \mathrm{ng} /$ $\mathrm{mL}$. The characteristics of the patients are presented in table 1.

Troponin levels were significantly correlated with the modified Rankin Scale on admission and on the day of discharge $(p=0.0001)$. The highest mean troponin levels on admission were in the group with the scores of 4 and 5 on the modified Rankin Scale and amounted to, respectively, $0.14 \pm 0.34 \mathrm{ng} / \mathrm{mL}$ and $0.54 \pm 2.11 \mathrm{ng} / \mathrm{mL}$ (Table 2 ).

People with quantitative disturbances of consciousness on admission featured significantly higher troponin levels ( $p$ $=0.011$ ). Only in 5 patients one of the stroke symptoms were seizures. The mean troponin level in this group was higher, but did not show a statistical significance and amounted to $0.396 \pm 0.82 \mathrm{ng} / \mathrm{mL}(\mathrm{p}=0.72)$. The previous transient ischemic attack (TIA- 5 patients) or ischemic stroke (23 patients) was associated with statistically significant higher troponin levels $(\mathrm{p}=0.023)$. 
Table 1: Characteristics of the study group

\begin{tabular}{|c|c|c|c|c|}
\hline Variable & $\begin{array}{c}\text { A } \\
\text { ischemic stroke } \\
n=128\end{array}$ & $\begin{array}{c}\text { B } \\
\text { secondary hemorrhagic stroke } \\
n=24\end{array}$ & $\begin{array}{c}\text { C } \\
\text { hemorrhagic stroke } \\
n=21\end{array}$ & $\begin{array}{c}\text { All patients } \\
n=173\end{array}$ \\
\hline Age (median) & $73.95 \pm 13.34$ & $74.00 \pm 13.72$ & $68.67 \pm 14.86$ & $73.32 \pm 13.66$ \\
\hline Female/Men & $72 / 56$ & $14 / 10$ & $10 / 11$ & $96 / 77$ \\
\hline Hypertension & 101 & 19 & 16 & 136 \\
\hline Diabetes mellitus & 35 & 9 & 5 & 49 \\
\hline Atrial Fibrillation & 40 & 11 & 6 & 57 \\
\hline Hyperlipidemia & 82 & 15 & 7 & 104 \\
\hline Smoking & 22 & 2 & 5 & 29 \\
\hline Quantitative disturbances in consciousness & 18 & 4 & 3 & 25 \\
\hline Previous stroke & 19 & 2 & 2 & 23 \\
\hline Previous TIA & 4 & 1 & 0 & 5 \\
\hline Deaths & 21 & 13 & 7 & 41 \\
\hline \multicolumn{5}{|c|}{ Radiology } \\
\hline MCA & 53 & 13 & 17 & 83 \\
\hline 2 arteries of the anterior circulation (ACA) & 13 & 8 & 3 & 24 \\
\hline PCA & 33 & 1 & 1 & 35 \\
\hline 2 arteries of basal ganglia area & 3 & 1 & 0 & 4 \\
\hline Cerebellum & 17 & 0 & 0 & 17 \\
\hline Lacunes & 9 & 0 & 0 & 9 \\
\hline
\end{tabular}

MCA-middle cerebral artery, ACA-anterior cerebral artery (ACA), PCA-posterior cerebral artery

Hyperlipidemia present in 104 patients had a statistically significant effect on statistically higher troponin levels ( 0.15 $\pm 0.80 \mathrm{ng} / \mathrm{mL}$ ). There was no statistical significance between the remaining examined risk factors for vascular disease and troponin level.

In $48 \%$ of the cases, vascular lesions involved the vascular area of the middle cerebral artery ( 83 patients), while the rarest ones were in the basal ganglia area ( 4 patients). In the case of ischemic stroke, lesions from 2 to 4 on the 10 -point scale prevailed, and in 2 cases the ischemic area covered an entire hemisphere. In most cases (9/21), a hemorrhagic stroke covered 5-6 cm in axial measurements. In the case of cerebellum changes, statistically significantly lower troponin levels were found than in the other groups $(p=0.050)$. There was also no relationship between the localization of lesions, their extent, and troponin levels.

\section{Discussion}

Increased troponin levels in patients with stroke are estimated at $5-34 \%[5-7,13,14]$. In our study, elevated troponin levels were found in $36 \%$ (63 patients). There were also significantly higher troponin levels in patients with previous TIA, ischemic stroke, and lipid metabolism disorders. Other risk factors for cardiovascular disease did not correlate with troponin levels. Similar results were obtained by Budincevic et al., who demonstrated a correlation between previous ischemic stroke and troponin levels $(p=0.032)$. The researchers did not find such a relationship between troponin levels and age, sex, or other risk factors for cardiovascular diseases (e.g. diabetes, hypertension and hyperlipidemia) among patients with acute ischemic stroke according to the TOAST classification [15]. Thalin et al. demonstrated a relationship between troponin levels and older age, previous ischemic stroke, chronic heart failure, kidney failure, and the extent of stroke. The hyperlipidemia indicator decreased with increasing troponin levels (in patients with normal troponin levels, the hyperlipidemia indicator was $25.6 \%$; in patients with significantly elevated troponin levels $>11 \mu \mathrm{g} / \mathrm{L}$, the index was $5.0 \%$ ) [16]. Song et al. observed a relationship between an increase in troponin levels and stroke associated with either large-vessel atherosclerosis $(p=0.045)$ or embolic mechanism ( $p=0.011$ ) according to the TOAST classification [17]. In our study, elevated mean troponin levels were found in patients with ischemic stroke followed by hemorrhagic transformation. There was no relationship between extent of stroke, its localization, and troponin level. Hasiri et al. demonstrated higher troponin levels in ischemic stroke located in the ACA territory in relation to the PCA territory $(0.08 \pm 0.22$ vs. 0.06 $\pm 0.21 \mu \mathrm{g} / \mathrm{L}$ ) [18]. Song et al. in their analysis of the clinical data of 416 patients with ischemic stroke and troponin cTnT levels identified a group of 45 patients $(10.1 \%)$ with elevated troponin levels, in whom they demonstrated significantly more frequent infiltration of the insular cortex $(p=0.021)$, brain stem $(\mathrm{p}=0.038)$, and multiple territorial infarction $(\mathrm{p}=$ 0.047). Many authors draw attention to the highest troponin levels in patients with ischemic stroke with an infiltration of the insular cortex $[6,14,17,18]$. This increases the risk of a critical cardiovascular incident associated with a damage to four cortical areas, i.e. insular cortex, parietal cortex, anterior 
Table 2: Mean troponin levels depending on the type of stroke, localization, the extent of stroke, and modified Rankin Scale.

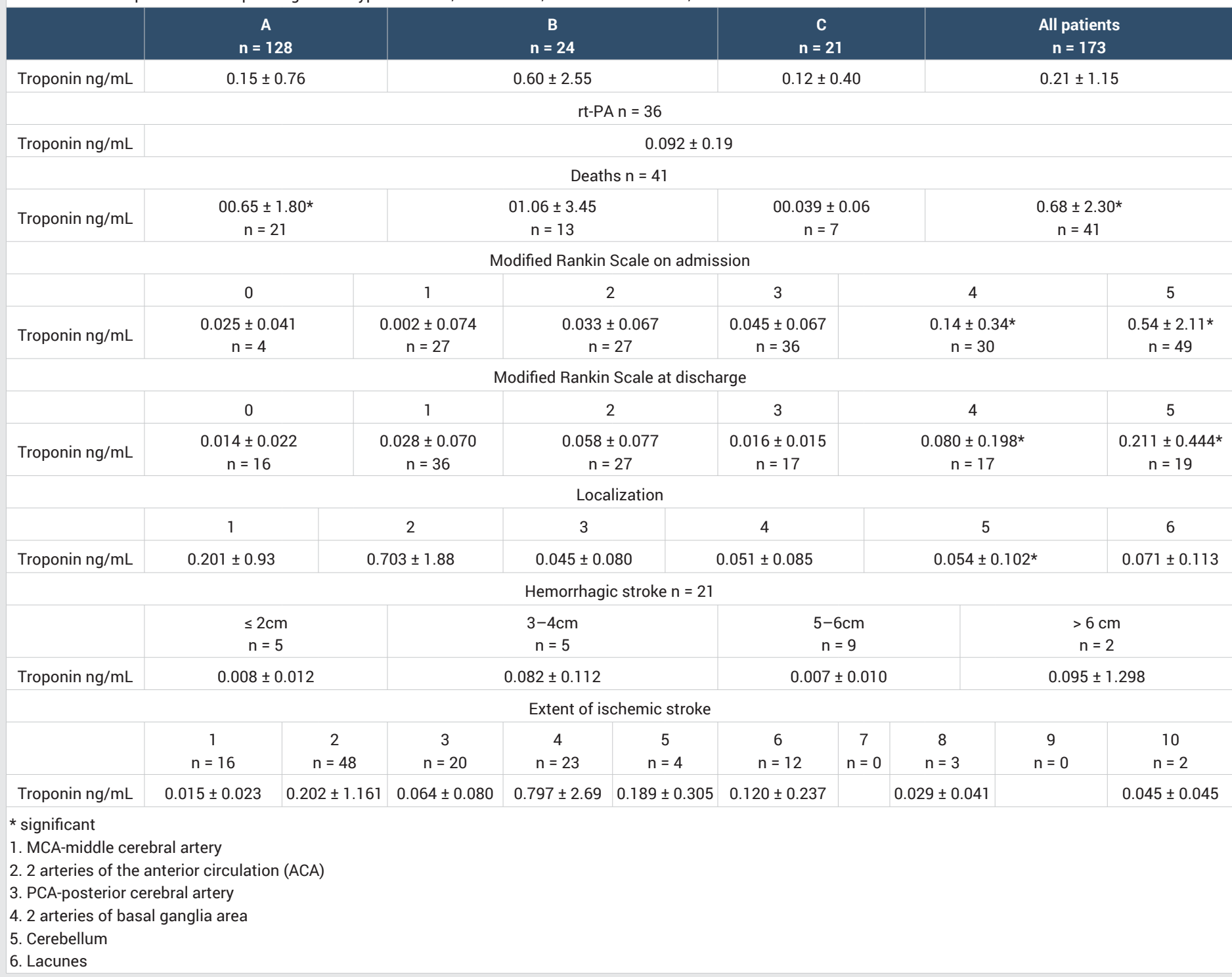

temporal lobe, and ventromedial prefrontal cortex. Damage to these areas of the cerebral cortex increases the risk of an excessive activation of cardiac sympathetic fibers and sudden arrhythmias. The insular cortex is a central component of the autonomic nervous system. In stroke affecting the insular cortex, a significant reduction in the heart rate variability (HRV) was observed. In multicenter studies [19-21], it was demonstrated that the localization of stroke near the left side of the insular cortex significantly increases the risk of cardiac complications (myocardial infarction, sudden death) accompanied by increased sympathetic nervous activity and biochemical markers of heart failure (elevated troponin $\mathrm{T}$ levels). In turn, in strokes affecting the right insular cortex, bradycardia with a fall in arterial pressure is fairly frequent [22].

Increased levels of cardiac troponins (cTn) in patients with stroke are associated with poor prognosis and increased mortality [5,6,15-17,23-26]. Higher cTn levels are found in older patients with heart or kidney failure, ischemic heart disease, and atrial fibrillation. Our results confirm the data collected by other authors. The highest levels of troponin were found in patients with quantitative consciousness disorders on admission, convulsive seizures, and in patients with disability scores 4 and 5 according to the modified Rankin Scale. Considerably elevated troponin levels were demonstrated in patients who died during hospitalization. These results are consistent with the data in literary references, where significantly higher troponin levels are associated with poor prognosis and occur in patients with higher scores according to the NIHSS scale and the modified Rankin Scale [18]. Similar correlations were not found in patients with hemorrhagic stroke.

The pathomechanism of troponin release in patients with stroke can be associated with co-occurrence of acute coronary syndrome. In the randomized RANTTAS study (Randomized Trial of Tirilazad Mesylate in Acute Stroke), acute coronary syndromes occurred in $6 \%$ of patients with stroke and more than $25 \%$ of patients had stenosis in coronary arteries, coronarography confirmed $[27,28]$. In the TRELAS study (Troponin Elevation in Acute Ischemic Stroke), an analysis was performed of atherosclerotic lesions in coronary vessels of patients with acute coronary syndrome without ST segment 
elevation (NSTE-ACS). In addition, an analysis was performed in patients with cerebral stroke with co-occurring elevated cTn levels. In patients with ischemic stroke, the culprit lesion ( 7 out of 29 versus 23 out of $29, p<0.001$ ) or ischemic heart disease with significant obstructive coronary artery disease were less frequent (15 out of 29 versus 23 out of $29, p=0.02$ ) [7,23].

Elevated cTn levels in patients with stroke may also be caused by neurogenic damage to cardiomyocytes as a result of autonomic nervous system activation or a disproportion between oxygen supply and demand by myocardial cells, leading to myocardial cell necrosis. Increased sympathomimetic activity induces an excessive release of catecholamines in the myocardium with a damage and dysfunction of the myocardium. This phenomenon is referred to as neurogenic stunned myocardium (NSM) [25]. Currently, it is suggested to include NSM in the group of stress-induced cardiomyopathy, similarly to Takotsubo cardiomyopathy, cardiomyopathy in the course of pheochromocytoma, and cardiomyopathy of the critically ill, e.g. in the course of sepsis. The pathomechanism of NSM formation is unclear. NSM occurs in patients with acute damage to the insular cortex, vascularized by the middle cerebral artery [29-32]. A damage to the insular cortex and hypothalamus leads to toxic release of catecholamines from sympathetic nerve endings. An excessive stimulation of postsynaptic receptors results in prolonged opening of calcium channels that depend on $ß 1$-adrenergic receptors. This prolongs the interaction of actin and myosin, leading to depletion of ATP reserves and mitochondrial dysfunction. An increased concentration of calcium ions in the cell results in release of free radicals and peroxidation of cell membranes. This leads to death of some of the heart cells, which is histopathologically referred to as myocardial contraction band necrosis and involves local myocytolysis without ischemic necrosis, myofibrillar degeneration, and formation of irregular transverse fibers. These changes are maximally subendocardial and minimal at the heart apex. Their severity is consistent with sympathetic irradiation, and not with vascularization. The development of NSM also plays a role in the parasympathetic system by modulating the inflammatory response induced by acute pathology within the central nervous system, e.g. a subarachnoid hemorrhage. In the case of NSM, the increase in cTnT is usually moderate. Due to the possibility of the stunned heart syndrome in patients with stroke, early cardiac function monitoring is recommended.

\section{Conclusion}

* A moderate increase in troponin was observed in patients with cerebral stroke.

* Elevated troponin levels indicated the lesion size and correlated with the degree of disability.

* High troponin levels can be a prognostic factor in the course of stroke.

\section{References}

1. Tesson A, Abdo R, Kamath A, Sutter J, Cline R, et al. (2018) HEART failure? Episodes of missed major cardiac events when applying the HEART pathway to an observation unit population. Crit Pathw Cardiol 17: 88-94. Link: https://goo.gl/TVen7Y
2. Noorvash D, Ramos R, Hatch L, Muck A, Olson AS (2018) Assessment of the utility of ordering a troponin in low- and intermediate-risk patients presenting to the Emergency Department with supraventricular tachycardia: A retrospective chart review. J Emerg Med 55: 1-6. Link: https://goo.gl/v9mAjL

3. Hedberg P, Valkama J, Suvanto E, Pikkujämsä S, Ylitalo K (2006) Evaluation of innotrac aio! Second-generation cardiac troponin I assay: the main characteristics for routine clinical use. J Autom Methods Manag Chem 2006 39325. Link: https://goo.gl/rqTxC6

4. Bellan M, Pirisi M, Bellomo G, Sainaghi PP (2017) A case of false positive Troponin I in a patient affected by cryoglobulinemic vasculitis. Reumatismo 69: 40-42. Link: https://goo.gl/MN75mi

5. Batal O, Jentzer J, Balaney B, Kolia N, Hickey G, et al. (2016) The prognostic significance of troponin I elevation in acute ischemic stroke. Journal of Critical Care 31: 41-47. Link: https://goo.gl/CLGVT2

6. Abdi S, Oveis-Gharan S, Sinaei F, Ghorbani A (2015) Elevated troponin T after acute ischemic stroke: Association with severity and location of infarction. Iran J Neurol 14: 35-40. Link: https://goo.gl/i6R1HU

7. Mochmann HC, Scheitz JF, Petzold GC, Haeusler KG, Audebert HJ, et al (2016) Coronary angiographic findings in acute ischemic stroke patients with elevated cardiac troponin: The troponin elevation in acute ischemic stroke (TRELAS) study. Circulation 133: 1264-1271. Link: https://goo.gl/TFBty7

8. VanHouten J, Fricker G, Collins B, Bhatia R, Ellis C, et al. (2018) Circulating troponin I level in patients with acute ischemic stroke. Curr Neurol Neurosci Rep 18: 32. Link: https://goo.gl/21CLNL

9. Willeit P, Welsh P, Evans JDW, Tschiderer L, Boachie C, et al. (2017) Highsensitivity cardiac troponin concentration and risk of first-ever cardiovascular outcomes in 154,052 participants. J Am Coll Cardiol 70: 558-568. Link: https://goo.gl/N8N35Y

10. Sacco RL, Kasner SE, Broderick JP, Caplan LR, Connors JJ, et al. (2013) An updated definition of stroke for the 21 st century: A statement for healthcare professionals from the American Heart Association/American Stroke Association. Stroke 44: 2064-2089. Link: https://goo.gl/tSr3vL

11. Dijkland SA, Voormolen DC, Venema E, Roozenbeek B, Polinder S, et al. (2018) Utility-weighted modified Rankin Scale as primary outcome in stroke trials: A simulation study. Stroke 49: 965-971. Link: https://goo.gl/CTaQYU

12. Chaisinanunkul N, Adeoye O, Lewis RJ, Grotta JC, Broderick J, et al. (2015) Adopting a patient-centered approach to primary outcome analysis of acute stroke trials using a utility-weighted modified Rankin Scale. Stroke 46: 22382243. Link: https://goo.gl/ZYJVWW

13. Lasek-Bal A, Kowalewska-Twardela T, Gąsior Z, Warsz-Wianecka A, Haberka $M$, et al. (2014) The significance of troponin elevation for the clinical course and outcome of first-ever ischaemic stroke. Cerebrovasc Dis 38: 212-218. Link: https://goo.gl/wYsZfd

14. Scheitz J, Mochmann HC, Erdur H, Tütüncü S, Haeusler KG, et al. (2014) Prognostic relevance of cardiac troponin $T$ levels and their dynamic changes measured with a high-sensitivity assay in acute ischaemic stroke: Analyses from the TRELAS cohort. Int J Cardiol 177: 886-893. Link: https://goo.gl/q3p6zf

15. Budincevic H, Sremec J, Crnac P, Ostojic V, Galic E, et al. (2017) Impact of troponin I on outcome of ischemic stroke patients. Rom J Intern Med 55: 1922. Link: https://goo.gl/XzHehs

16. Thalin C, Rudberg AS, Johansson F, Jonsson F, Laska AC, et al. (2015) Elevated troponin levels in acute stroke patients predict long-term mortality. J Stroke Cerebrovasc Dis 24: 2390-2396. Link: https://goo.gl/ugYBts

17. Song HS (2008) Cardiac troponin T elevation after stroke: Relationships between elevated serum troponin $\mathrm{T}$, stroke location, and prognosis. $\mathrm{J}$ Clin Neurol 4: 75-83. Link: https://goo.gl/mgAqjw 
18. Hasirci B, Okay M, Agircan D, Kocer A (2013) Elevated troponin level with negative outcome was found in ischemic stroke. Cardiovasc Psychiatry Neurol 2013: 953672. Link: https://goo.gl/3a4HtJ

19. Rincon F, Dhamoon M, Moon Y, Paik MC, Boden-Albala B, et al. (2008) Stroke location and association with fatal cardiac outcomes: Northern Manhattan Study (NOMAS). Stroke 39: 2425-2431. Link: https://goo.gl/fTyHJv

20. Oppenheimer SM, Kedem G, Martin WM (1996) Left-insular cortex lesions perturb cardiac autonomic tone in humans. Clin Auton Res 6:131-140. Link: https://goo.gl/cvMZSf

21. Laowattana S, Zeger SL, Lima JA, Goodman SN, Wittstein IS, et al. (2006) Left insular stroke is associated with adverse cardiac outcome. Neurology 66: 477-483. Link: https://goo.gl/gKfrhS

22. Oppenheimer S, Hachinski V (1992) Complications of acute stroke. Lancet 339: 721-724. Link: https://goo.gl/zRQKmW

23. Scheitz JF, Mochmann HC, Nolte $\mathrm{CH}$, Haeusler KG, Audebert HJ, et al. (2011) Troponin elevation in acute ischemic stroke (TRELAS)protocol of a prospective observational trial. BMC Neurol 11: 98. Link: https://goo.gl/PthSBW

24. Su YC, Huang KF, Yang FY, Lin SK (2016) Elevation of troponin I in acute ischemic stroke. Peer J 4: e1866. Link: https://goo.gl/MTLY5y

25. Dous G, Grigos A, Grodman R (2017) Elevated troponin in patients with acute stroke-is it a true heart attack? Egypt Heart J 69: 165-170. Link: https://goo.gl/GzBiFT
26. Yoon M, Yang PS, Jang E, Yu HT, Kim TH, et al. (2018) Dynamic changes of cha2ds2-vasc score and the risk of ischaemic stroke in Asian patients with atrial fibrillation: A nationwide cohort study. Thromb Haemost 18: 1296-1304. Link: https://goo.gl/1A8p4s

27. Johnston KC, Li JY, Lyden PD, Hanson SK, Feasby TE, et al. (1998) Medical and neurological complications of ischemic stroke: experience from the RANTTAS trial. Stroke 29: 447-453. Link: https://goo.gl/UUdCYa

28. Christensen H, Boysen G, Christensen AF, Johannesen HH (2005) Insular lesions, ECG abnormalities, and outcome in acute stroke. J Neurol Neurosurg Psychiatry 76: 269-271. Link: https://goo.gl/qRc8Hq

29. Ripoll JG, Blackshear JL, Díaz-Gómez JL (2018) Acute Cardiac Complications in Critical Brain Disease. Neurosurg Clin N Am 29: 281-297. Link: https://goo.gl/P7jGwq

30. Biso S, Wongrakpanich S, Agrawal A, Yadlapati S, Kishlyansky M, et al. (2017) A review of neurogenic stunned myocardium. Cardiovasc Psychiatry Neurol 2017: 5842182. Link: https://goo.gl/gVUVog

31. Mierzewska-Schmidt M, Gawecka A (2015) Neurogenic stunned myocardium-do we consider this diagnosis in patients with acute central nervous system injury and acute heart failure? Anaesthesiol Intensive Ther 47: 175-180. Link: https://goo.gl/SqdTX7

32. Murthy SB, Shah S, Venkatasubba Rao CP, Suarez JI, Bershad EM (2014) Clinical characteristics of myocardial stunning in acute stroke. J Clin Neurosci 21: 1279-1282. Link: https://goo.gl/ULKCKRns

Copyright: (C) 2018 Dziadkowiak E, et al. This is an open-access article distributed under the terms of the Creative Commons Attribution License, which permits unrestricted use, distribution, and reproduction in any medium, provided the original author and source are credited. 